\title{
Tribo-corrosion response of additively manufactured
} high-entropy alloy

Jibril Shittu (D) ${ }^{1}$, Maryam Sadeghilaridjani ${ }^{1}$, Mayur Pole ${ }^{1}$, Saideep Muskeri ${ }^{1}$, Jie Ren ${ }^{2}$, Yanfang Liu ${ }^{2}$, Ismael Tahoun ${ }^{2}$, Harpreet Arora $^{3}$, Wen Chen $^{2}$, Narendra Dahotre ${ }^{1}$ and Sundeep Mukherjee iD $^{1 凶}$

High-entropy alloys (HEAs) with multiple principal elements represent a paradigm shift in structural alloy design and show excellent surface degradation resistance in corrosive environment. Here, the tribo-corrosion response of laser-engineered net-shaped $\mathrm{CoCrFeMnNi} \mathrm{HEA} \mathrm{was} \mathrm{evaluated} \mathrm{in} 3.5 \mathrm{wt} \% \mathrm{NaCl}$ solution at room temperature. The additively manufactured (AM-ed) CoCrFeMnNi showed five times lower wear rate, regenerative passivation, and nobler corrosion potential during tribo-corrosion test compared to its arc-melted counterpart. A significant anisotropy was seen in the tribo-corrosion response with $45^{\circ}$ to the build direction showing better performance compared to tests along the build direction and perpendicular to it. The open circuit potential curves were characterized by a sharp drop to more negative values as wear began, followed by continuous change for the active tribo-corrosion duration and finally a jump to nobler value at the end of the test indicating excellent surface re-passivation for the AM-ed alloy. The superior tribo-corrosion resistance of $\mathrm{AM}$-ed $\mathrm{CoCrFeMnNi}$ was attributed to the refined microstructure and highly protective surface passivation layer promoted by the sub-grain cellular structure formed during additive manufacturing. These results highlight the potential of utilizing additive manufacturing of HEAs for use in extreme environments that require a combination of tribo-corrosion resistance, mechanical durability, extended service life, and net shaping with low dimensional tolerance.

npj Materials Degradation (2021)5:31; https://doi.org/10.1038/s41529-021-00177-2

\section{INTRODUCTION}

High-entropy alloys (HEAs), also known as complex concentrated alloys, represents a paradigm shift in alloy design strategy that demonstrate excellent mechanical properties and surface degradation resistance ${ }^{1-5}$. There remains a tremendous interest in advanced manufacturing and processing of different HEA systems due to the tunability of properties for a wide range of structural and functional applications ${ }^{1,6,7}$. Laser-engineered net shaping (LENS) has proven to be a versatile manufacturing route for fabrication of complex geometries with enhanced microstructural features that are difficult to obtain by conventional processing ${ }^{8,9}$. The desirable attributes of LENS over other additive manufacturing (AM) techniques include rapid deposition time, microstructural refinement, and the capability for obtaining functionally graded and layered materials for tailored applications ${ }^{10-15}$. The inherent localized heating and rapid cooling $\left(>10^{3} \mathrm{~K} / \mathrm{s}\right)$ during $\mathrm{AM}$ tends to suppress elemental segregation and phase separation typically seen in multi-component alloys synthesized using conventional routes ${ }^{16-19}$. There are several reports on AM of HEAs that include laser powder bed fusion (also called selective laser melting ${ }^{20-23}$ as well as LENS $^{24}$. However, there are very few reports and limited understanding of the degradation mechanisms in additively manufactured (AM-ed) HEAs in terms of their wear, corrosion, and tribo-corrosion behavior.

Tribo-corrosion involves the synergistic combination of wear and corrosion that leads to accelerated material degradation ${ }^{25-28}$. Tribo-corrosion is commonly seen in many applications including bio-implants, hydraulic systems, nuclear power plants, chemical reactors, marine industries, and deep-sea oil drilling rigs and pumps ${ }^{29,30}$. HEAs offer a wide range of tunability of their surface properties due to the multi-principal alloying approach, which makes them appealing for tribo-corrosion applications. Prior studies on AM of HEAs have shown desirable mechanical properties ${ }^{31-33}$, fine cellular microstructure ${ }^{20,23,34}$, and excellent wear and corrosion behavior ${ }^{3,35,36}$. However, there are no reports so far on the tribo-corrosion behavior of AM-ed HEAs and the associated structure-property-performance relationships.

Here, tribo-corrosion behavior of AM-ed (via LENS) CoCrFeMnNi HEA was studied and compared with its counterpart synthesized by conventional vacuum arc melt casting. The equimolar $\mathrm{CoCrFeMnNi}$ alloy was chosen because it is one of the most widely studied HEAs, with numerous reports on microstructural characterization, mechanical behavior, corrosion, and wear ${ }^{21-23,37,38}$. However, there are no reports on tribo-corrosion degradation of this HEA. In addition, there is limited understanding of the effect of AM microstructure on wear-corrosion synergy. Here, we evaluated the effect of AM build orientation on tribo-corrosion response. The correlation between coefficient of friction (COF) and open circuit potential (OCP) was studied by our experimental setup to explain the tribo-corrosion degradation behavior of AM-ed versus as-cast CoCrFeMnNi HEA.

\section{RESULTS AND DISCUSSION \\ Microstructural characterization}

Near-full density was obtained for the AM-ed CoCrFeMnNi alloy under optimized processing conditions. The corresponding microstructural characterization are summarized in Fig. 1. Scanning electron microscopy (SEM) image in Figure 1a shows some spherical micro-scale pores (indicated by arrows) of size less than $10 \mu \mathrm{m}$. These pores likely originated from the powder feedstock and evaporation of constituent elements ${ }^{22}$ as well as gas entrapment from the melt pool turbulence ${ }^{39}$. Figure $1 \mathrm{~b}$ shows

\footnotetext{
${ }^{1}$ Department of Materials Science and Engineering, University of North Texas, Denton, TX 76203, USA. ${ }^{2}$ Department of Mechanical Engineering, University of Massachusetts, Amherst, MA 01003, USA. ${ }^{3}$ Department of Mechanical Engineering, School of Engineering, Shiv Nadar University, Greater Noida, Uttar Pradesh 201314 , India. ${ }^{\circledR}$ email: sundeep. mukherjee@unt.edu
} 

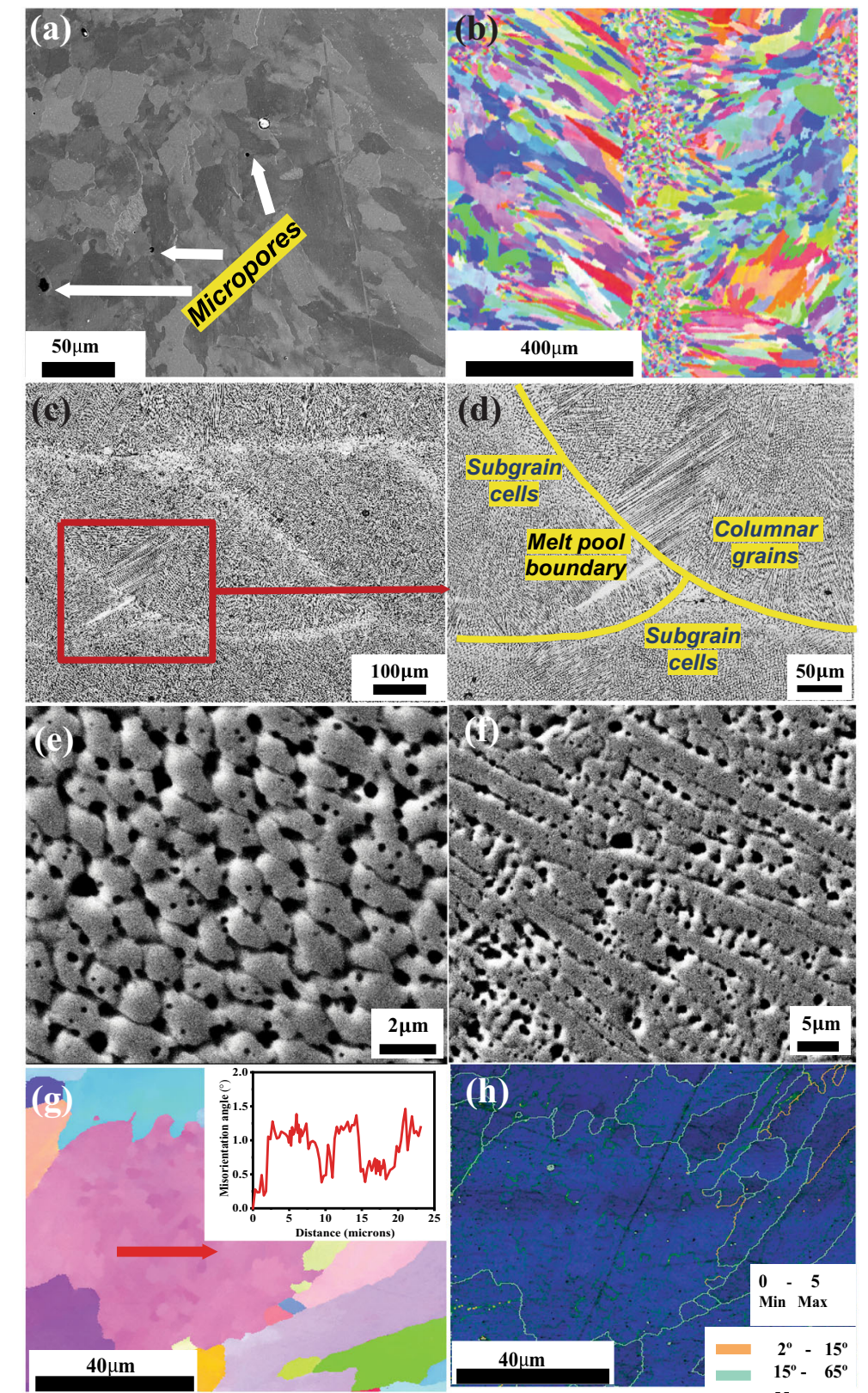

(d)
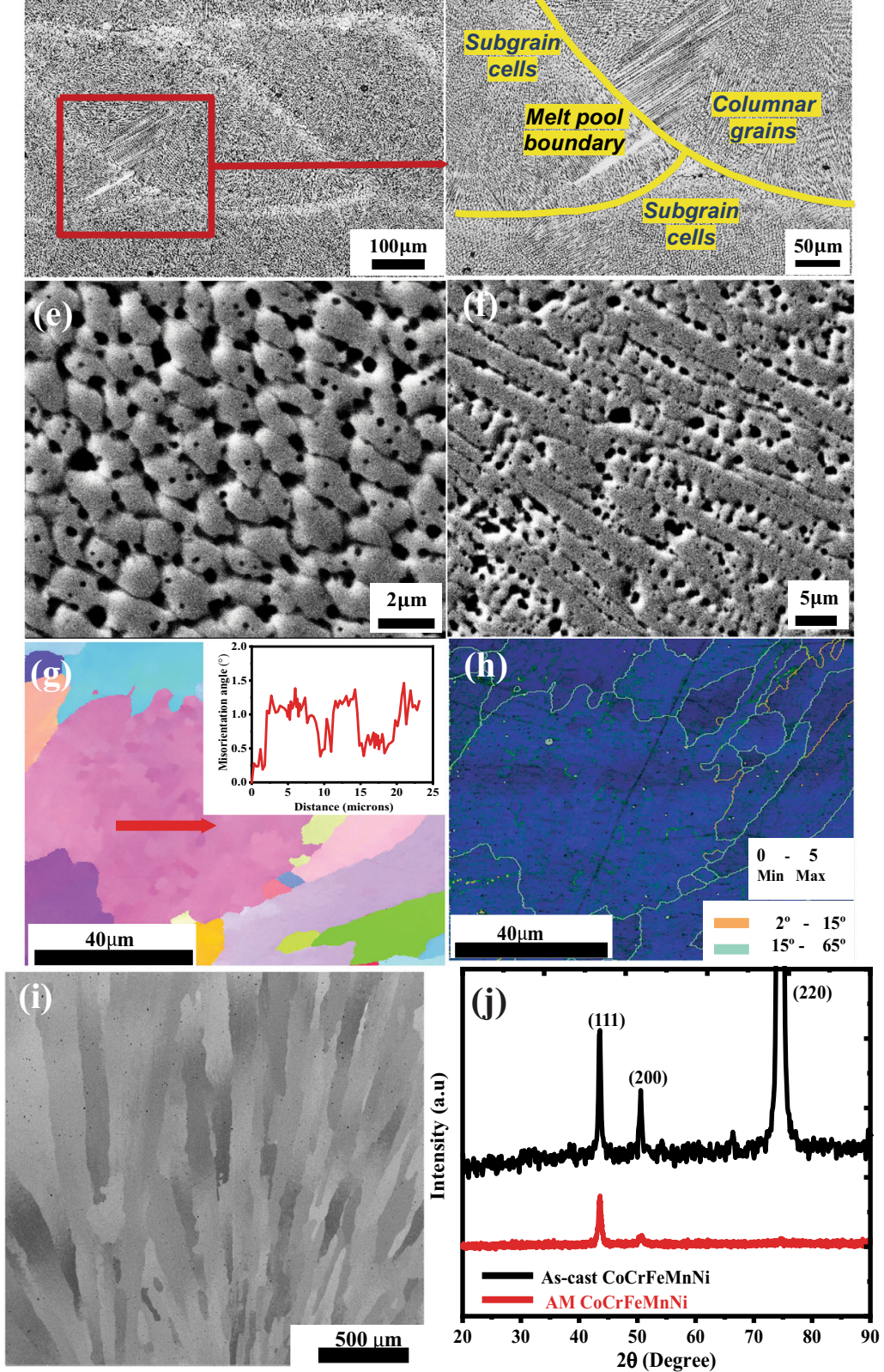

Fig. 1 Microstructural analysis. a SEM image of laser-engineered net-shaped CoCrFeMnNi alloy showing near-full density microstructure with some micropores indicated by arrows. b EBSD IPF map along build direction showing columnar grains. c SEM image of as-cast CoCrFeMnNi alloy with columnar grains. d Optical microscopy $(\mathrm{OM})$ image of the longitudinal section of the LENS sample. e Magnified image of the square box area in (d) showing melt pool, columnar grains, and sub-grain cells. f SEM image showing transverse section of the sub-grain cellular structures. g SEM image showing the longitudinal section of the sub-grain cellular structures. $\mathbf{h}$ High-magnification IPF image showing local misorientation within primary grains and the inset showing misorientation profile along the arrow. $\mathbf{i}$ Corresponding kernel average misorientation (KAM) map indicating dislocation arrays along the cell boundaries. $\mathbf{j}$ X-ray diffraction patterns showing single-phase FCC structure for AM-ed and as-cast CoCrFeMnNi. 


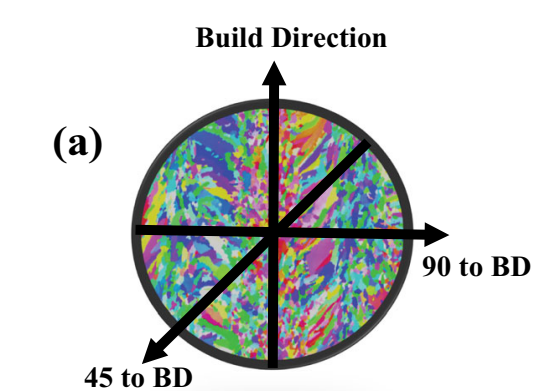

$\mathrm{BD}=$ Build direction
45 to $\mathrm{BD}=45^{\circ}$ to build direction
90 to $\mathrm{BD}=90^{\circ}$ to build direction

AM CoCrFeMnNi Working Electrode

\section{stabilization}

(d)

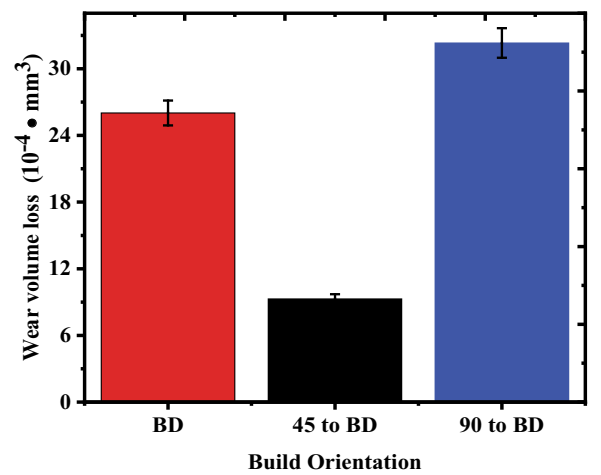

(b)

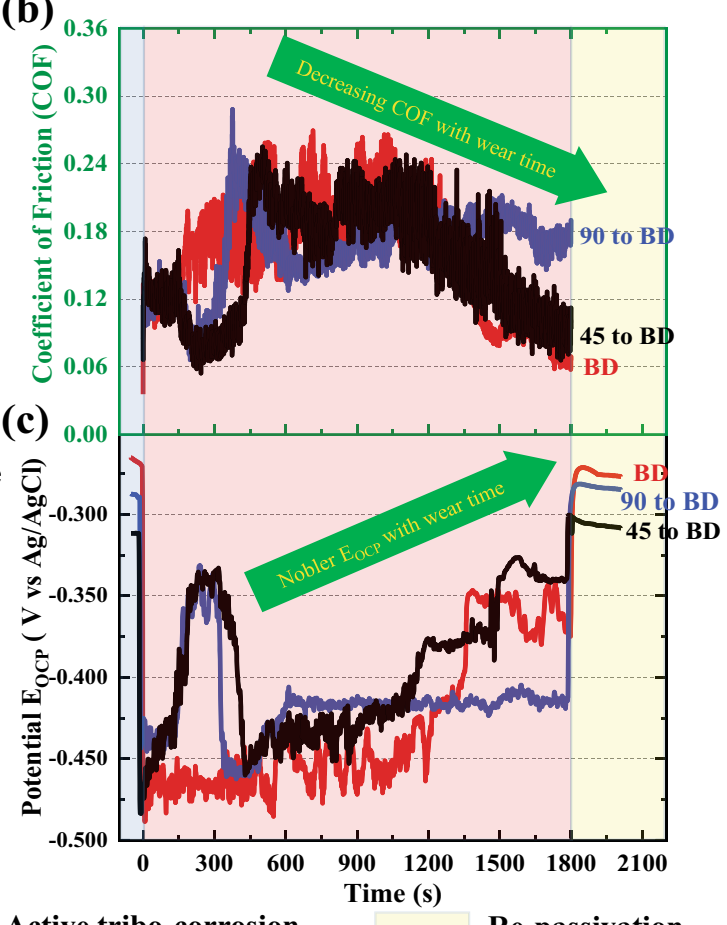

Active tribo-corrosion

(e)

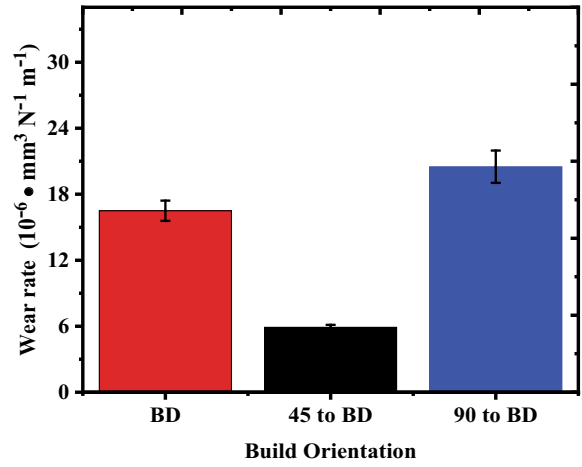

Fig. 2 Effect of build orientation on tribo-corrosion behavior of AM-ed CoCrFeMnNi. a Schematic representation of the three orientations studied. b Coefficient of friction. c Open circuit potential. d Wear volume loss. e Wear rate for the three build orientations.

the inverse pole figure (IPF) map of the AM-ed sample along the build direction (BD) with columnar grains of average size $\sim 36.4 \pm$ $23.4 \mu \mathrm{m}$. The AM melt pool, semi-circular in shape, had a diameter-to-depth ratio of $5: 2$ and overlap rate of $60 \%$ with the adjacent pool as shown in Fig. 1c. Elongated columnar grains growing towards the melt pool center were formed near the melt pool boundary due to large thermal gradient $(G)$ and varying solidification rate $(R)$ as shown in the zoomed in section in Fig. $1 \mathrm{~d}$. The large thermal gradient and solidification rate leads to a solidification mode dependent on the degree of constitutional undercooling between the melt pool center and boundary ${ }^{40}$. This results in the microstructure ranging from equiaxed at the center to columnar at the boundary. Similar microstructural features of the melt pool have been previously reported ${ }^{41,42}$. Sub-grain cell structures with an average size of $\sim 2-3 \mu \mathrm{m}$ was observed within the melt pool (Fig. 1e). The occurrence of sub-grain cellular structures is typical of the rapid solidification conditions of the LENS process ${ }^{41}$. In the longitudinal section of the sub-grain cells (Fig. 1f), secondary columnar grains were seen, indicating side instabilities of the solid-liquid interface perpendicular to the primary growth direction with a transition of sub-grains from cellular to dendritic growth ${ }^{43}$. High-magnification electron backscattered diffraction (EBSD) analysis was performed to investigate fine sub-grain cells within the primary grains. The IPF and kernel average misorientation (KAM) maps are shown in Fig. 1g, $h$, respectively. The IPF map clearly shows local misorientations in the grain interior across the sub-grain cells. The average local misorientation between sub-grain cell structures along the arrow shown in the IPF image was $\sim 1.25^{\circ}$ as shown in the misorientation plot (inset of Fig. 1g), suggesting a build up of strain gradient in the AM-ed sample. Furthermore, many fine cell-like features in the size range of $2-3 \mu \mathrm{m}$ were observed in the KAM map (Fig. 1h), which may be attributed to arrays of geometrically necessary dislocations at the cell boundaries ${ }^{34,44}$. Microstructure of the as-cast CoCrFeMnNi alloy is shown in Fig. 1i with characteristic parallel columnar grains. The phases present in both AM-ed and as-cast CoCrFeMnNi were identified using XRD as shown in Fig. 1j. Both AM-ed and as-cast CoCrFeMnNi showed single-phase face-centered cubic (FCC) microstructure as previously reported $20,22,33,38$. 

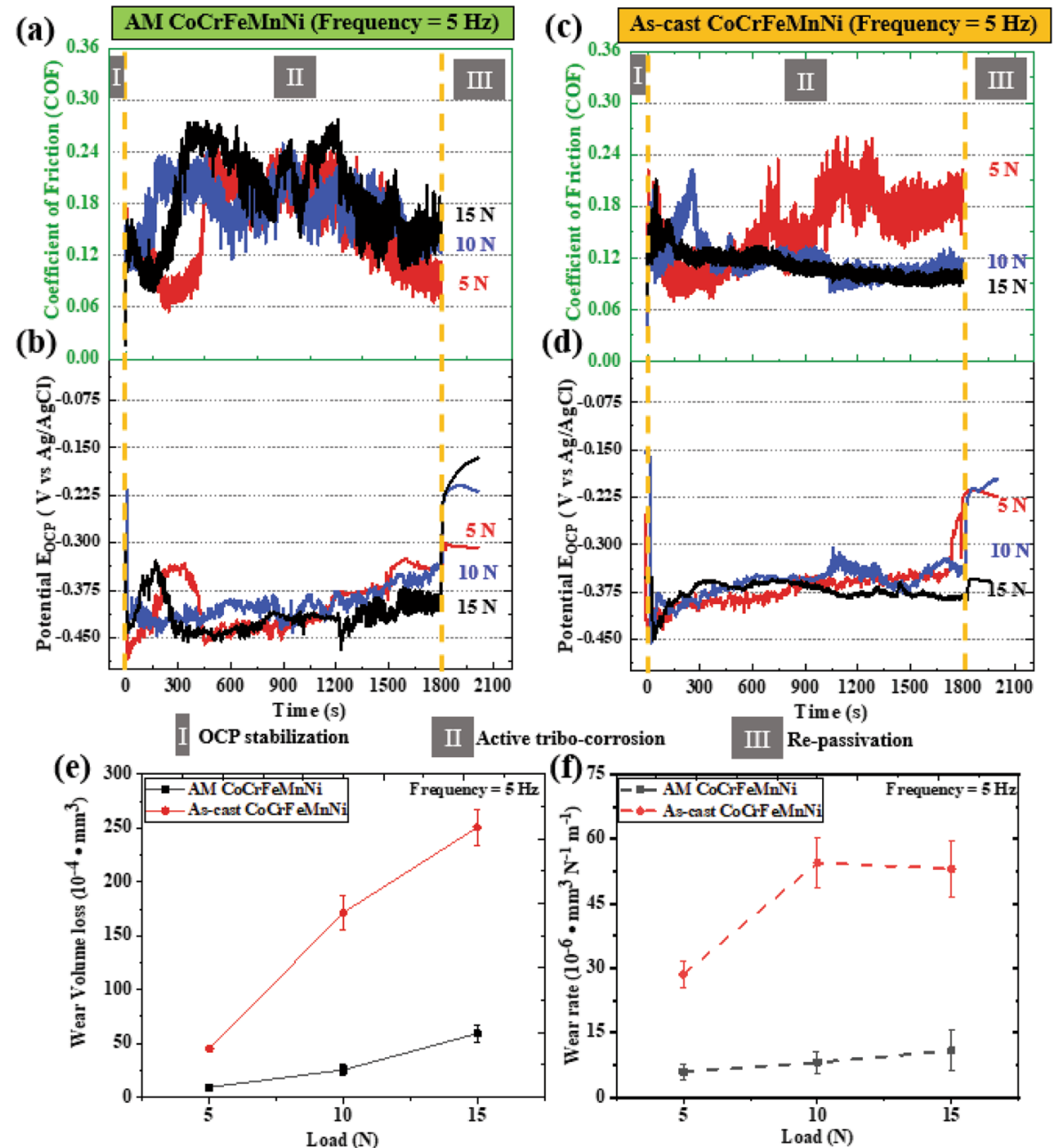

Fig. 3 Effect of normal load at $5 \mathrm{~N}, 10 \mathrm{~N}$, and $15 \mathrm{~N}$ on tribo-corrosion behavior CoCrFeMnNi. a Coefficient of friction (COF), and b open circuit potential $\left(E_{\text {ocp }}\right)$ as a function of load in $3.5 \mathrm{wt} \% \mathrm{NaCl}$ at $5 \mathrm{~Hz}$ frequency for AM CoCrFeMnNi. c COF, and $\mathbf{d}$ OCP as a function of load in $3.5 \mathrm{wt} \% \mathrm{NaCl}$ at $5 \mathrm{~Hz}$ frequency for as-cast CoCrFeMnNi. e Wear volume loss as a function of load for AM CoCrFeMnNi (solid black line) and ascast CoCrFeMnNi (solid red line) at a frequency of $5 \mathrm{~Hz}$. f Wear rate as a function of load at a frequency of $5 \mathrm{~Hz}$ for $\mathrm{AM} \mathrm{CoCrFeMnNi} \mathrm{(dashed}$ black line) versus as-cast CoCrFeMnNi (dashed red line).

\section{Effect of build orientation on tribo-corrosion of AM-ed CoCrFeMnNi}

Anisotropy resulting from AM build orientation ${ }^{21}$, grain refinement, and grain-size distribution directly affect the mechanical properties, wear behavior, and consequently tribo-corrosion response of alloys. The three orientations considered in the present study were: (i) along the build direction (BD), (ii) perpendicular to $\mathrm{BD}\left(90^{\circ}\right.$ to $\left.\mathrm{BD}\right)$, and (iii) $45^{\circ}$ to $\mathrm{BD}$, as marked in Fig. 2a. The results for COF and OCP are shown in Fig. 2b, $c$, respectively. The OCP curves in Fig. $2 c$ were characterized by a sharp drop to more negative values as wear began, followed by continuous change in OCP for the active tribo-corrosion duration, and finally a jump to nobler value at the end of the test indicating surface re-passivation. The sharp drops in OCP (Fig. 2c) corresponded exactly to the spikes in COF as reported previously for Ti6Al4V 45,46 . As OCP moved towards nobler values for the three orientations, both COF and wear rate decreased. The wear volume loss and wear rate for the three orientations are shown in Fig. $2 d$, e, respectively. The wear volume loss and wear rate along $45^{\circ}$ to $\mathrm{BD}$ was found to be lowest at $9.28 \times 10^{-4} \mathrm{~mm}^{3}$ and $5.9 \times 10^{-6}$ $\mathrm{mm}^{3} / \mathrm{Nm}$, respectively. This may be attributed to the orientation of most grains at $45^{\circ}$ to the $\mathrm{BD}$, thereby resulting in lower grainboundary density along that direction. Thus, $45^{\circ}$ to $B D$ showed the best tribo-corrosion resistance with lowest overall wear rate among the three directions studied, and was used for the remaining tests for comparison with the as-cast alloy.

\section{Effect of normal load on tribo-corrosion response}

To evaluate the tribo-corrosion behavior of both AM-ed and ascast $\mathrm{CoCrFeMnNi}$ in a dynamic loading environment, $5 \mathrm{~Hz}$ reciprocating frequency was used with varying normal loads of $5 \mathrm{~N}, 10 \mathrm{~N}$, and $15 \mathrm{~N}$. The COF and corresponding OCP for AM-ed $\mathrm{CoCrFeMnNi}$ are shown in Fig. 3a, b, respectively. At all three loads, a distinct drop in COF coincided exactly with increase in OCP between 50 and $450 \mathrm{~s}$, which was attributed to the breakdown in protective passive layer of the AM-ed CoCrFeMnNi. However, the surface re-passivated with further progression of the test as supported by the reduction in COF and shift in OCP towards nobler value. The average COF was in the range of 0.1-0.2 for the three loads for AM-ed CoCrFeMnNi (Fig. 3a). The COF and OCP recorded simultaneously for the as-cast $\mathrm{CoCrFeMnNi}$ are shown in Fig. 3c, d, respectively. At $5 \mathrm{~N}$ (red plot), COF decreased initially before rising continually to higher values while the OCP shifted towards nobler values with progression of the tribocorrosion test. At $10 \mathrm{~N}$ and $15 \mathrm{~N}$ loads, the COF curves (Fig. 3c) were relatively smooth while both the OCP curves (Fig. 3d) moved 


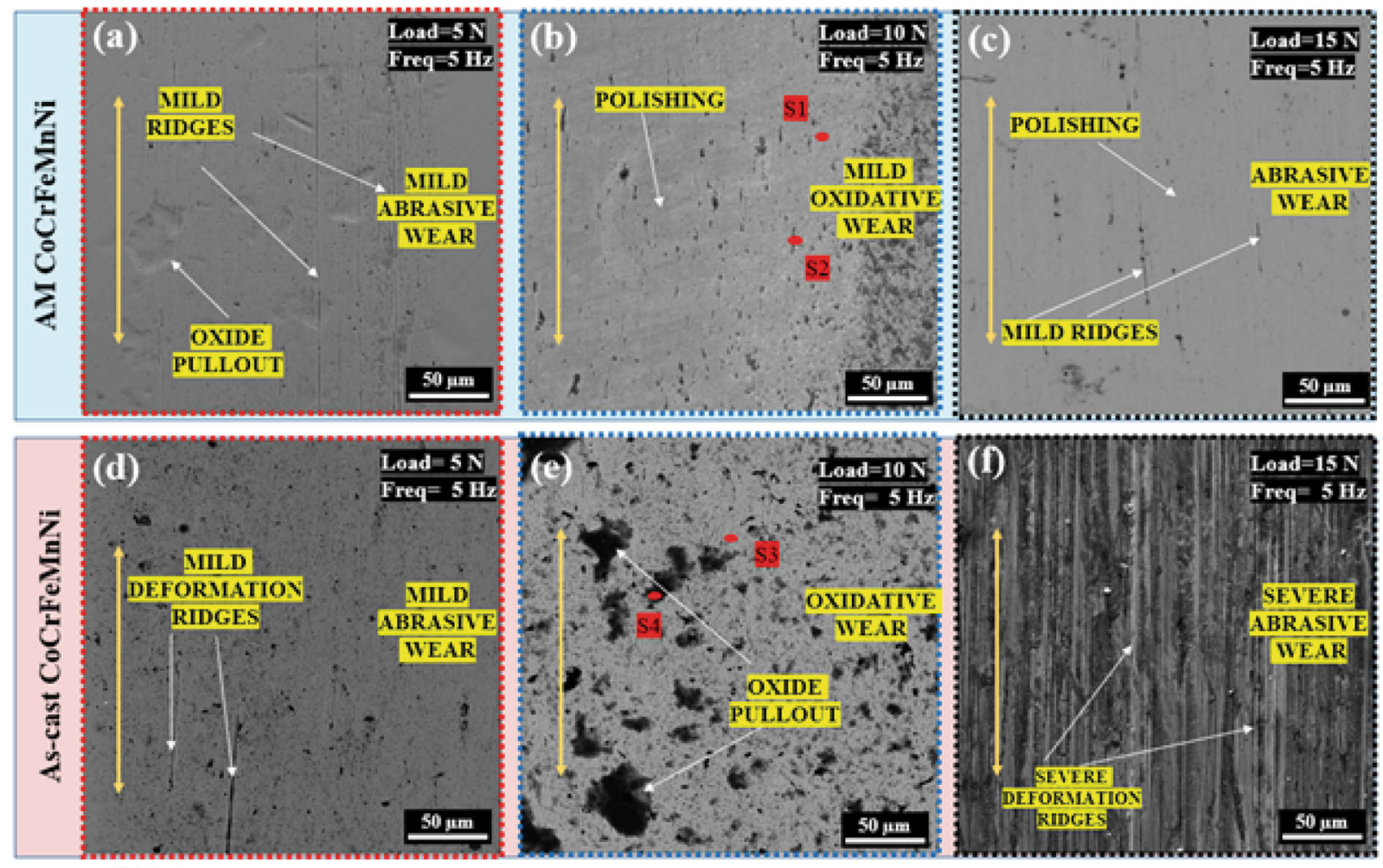

- EDS Spot

Fig. 4 Post-tribo-corrosion SEM micrograph of wear track morphology. a $5 \mathrm{~N}$ normal load tribo-corrosion of $\mathrm{AM}$ CoCrFeMnNi. b $10 \mathrm{~N}$ normal load tribo-corrosion of AM CoCrFeMnNi. c $15 \mathrm{~N}$ normal load tribo-corrosion of AM CoCrFeMnNi. d $5 \mathrm{~N}$ normal load tribo-corrosion of as-cast CoCrFeMnNi. e $10 \mathrm{~N}$ normal load tribo-corrosion of as-cast CoCrFeMnNi. f $15 \mathrm{~N}$ normal load tribo-corrosion of as-cast CoCrFeMnNi. Yellow double-sided arrows in the figures indicate the reciprocating sliding direction.

towards less noble values indicating the lack of passive layer regeneration. The average COF was in the range of $0.1-0.2$ for the three loads while average OCP was in the range of -0.45 to $-0.30 \mathrm{~V}$ (vs $\mathrm{Ag} / \mathrm{AgCl}$ ). The wear volume loss for both the AM-ed and as-cast CoCrFeMnNi, shown in Fig. 3e, increased monotonically with increase in load but at a different rate going from $5 \mathrm{~N}$ to $10 \mathrm{~N}$ than from $10 \mathrm{~N}$ to $15 \mathrm{~N}$ as contact stresses changed with increase in load. The overall wear volume loss for the as-cast CoCrFeMnNi was about six times higher compared to its AM-ed counterpart at all the studied loads. In Fig. 3f, the wear rate for AM CoCrFeMnNi (black dashed plot) showed a monotonic positive slope. While the as-cast CoCrFeMnNi (red dashed line) showed an increase in wear rate from $5 \mathrm{~N}$ to $10 \mathrm{~N}$, but a reduced wear rate going from $10 \mathrm{~N}$ to $15 \mathrm{~N}$. The overall wear rate for $\mathrm{AM}$ CoCrFeMnNi was about five times lower compared to as-cast CoCrFeMnNi at all loads. This was attributed to the refined microstructure and subgrain cellular structures in the case of AM-ed CoCrFeMnNi (shown in Fig. 1), providing greater deformation resistance and a more adherent surface passivation layer.

\section{Wear morphology and mechanism}

The surface morphologies of AM and as-cast CoCrFeMnNi HEA after reciprocating tribo-corrosion at different loads with a frequency of $5 \mathrm{~Hz}$ are shown in Fig. 4. Both alloys exhibited a change in wear mechanism as the load was varied from $5 \mathrm{~N}$ to $15 \mathrm{~N}$. Reciprocating sliding wear morphology of AM-ed alloy at $5 \mathrm{~N}$ in Fig. 4a showed typical abrasive wear with mild groves and deformation ridges parallel to the sliding direction along with some degree of oxide pullout. This was ascribed to the surface oxide layer being sufficiently thick and regenerative to provide normal load shielding and passivation. For $10 \mathrm{~N}$ load shown in Fig. $4 \mathrm{~b}$, a smoother profile with mild oxidative wear was seen because of increased normal load causing a polishing effect with smaller groves and ridges along with dark spots representing oxide patches. Spot energy dispersive spectroscopy (EDS) analysis of the wear track at points S1 and S2 in Fig. 4b showed oxygen content of 3.90 at $\%$ and 48.26 at\%, respectively, indicating the presence of oxide patches as summarized in Table 1. The change from mild abrasive wear to oxidative wear may be attributed to the increased normal load which tends to polish the surface as a hard-on-hard contact is formed with a lubricating oxide layer in between. For $15 \mathrm{~N}$ load (Fig. 4c), similar abrasive wear was observed with mild ridges and polishing effect. The stable and regenerative passive layer for $\mathrm{AM}$ CoCrFeMnNi contributed to its better tribo-corrosion behavior. For the as-cast alloy at $5 \mathrm{~N}$ and $5 \mathrm{~Hz}$ (Fig. 4d), abrasive wear was observed similar to $\mathrm{AM}$ CoCrFeMnNi with mild ridges parallel to the sliding direction and dark oxide patches. This was ascribed to the protective passive layer being insufficiently thick, less regenerative, and unable to shield and passivate to the extent of the corresponding AM-ed alloy. At $10 \mathrm{~N}$ load (shown in Fig. 4e), oxidative wear was observed with large sections of oxide pullout from the combination of high load and corrosive environment that deteriorated the protective passive layer and exposed the underlying alloy. Spot EDS analysis of the wear track at points S3 and S4 in Fig. 4e showed oxygen content of 4.15 at\% and 45.24 at\%, respectively, again indicating the presence of oxide patches as summarized in Table 1. The larger pullout of oxide patches indicates relatively lower stability of the surface oxide layer for the as-cast alloy. At $15 \mathrm{~N}$ load (Fig. $4 \mathrm{f}$ ), severe deformation ridges and deterioration of the surface oxide led to severe abrasive wear. Thus, the AM-ed alloy showed better tribo-corrosion behavior and stable regenerative oxide compared to its as-cast counterpart under varying loads, which supports the results of OCP and COF discussed in the previous sections. 
Table 1. EDS elemental composition at $10 \mathrm{~N}$ wear track.

\begin{tabular}{llrrrrrrr}
\hline CoCrFeMnNi sample & Spot & \multicolumn{2}{c}{ Element (at\%) } & & & \\
\cline { 2 - 8 } & & \multicolumn{1}{c}{$\mathrm{O}$} & $\mathrm{Al}$ & $\mathrm{Cr}$ & $\mathrm{Mn}$ & $\mathrm{Fe}$ & $\mathrm{Co}$ & $\mathrm{Ni}$ \\
\hline AM 10 N & $\mathrm{S} 1$ & 3.90 & 0.22 & 19.50 & 19.15 & 19.20 & 19.59 & 18.43 \\
& $\mathrm{~S} 2$ & 48.26 & 10.89 & 9.54 & 8.32 & 8.32 & 7.64 & 7.03 \\
as-cast 10 N & $\mathrm{S} 3$ & 4.15 & 0.45 & 18.62 & 20.12 & 19.06 & 18.44 & 19.15 \\
& $\mathrm{~S} 4$ & 45.24 & 23.25 & 9.68 & 4.61 & 7.41 & 5.36 & 4.43 \\
\hline
\end{tabular}

Table 2. LENS processing parameters for additively manufactured CoCrFeMnNi HEA.

\begin{tabular}{lllll}
\hline Laser powder $(\mathrm{W})$ & Scan speed $(\mathrm{mm} / \mathrm{min})$ & $\mathrm{Z}$ increment $(\mathrm{mm})$ & Hatching distance $(\mathrm{mm})$ & Powder feed rate $(\mathrm{g} / \mathrm{min})$ \\
\hline 250 & 762 & 0.35 & 0.4 & 6.5 \\
\hline
\end{tabular}

(a)

(c)
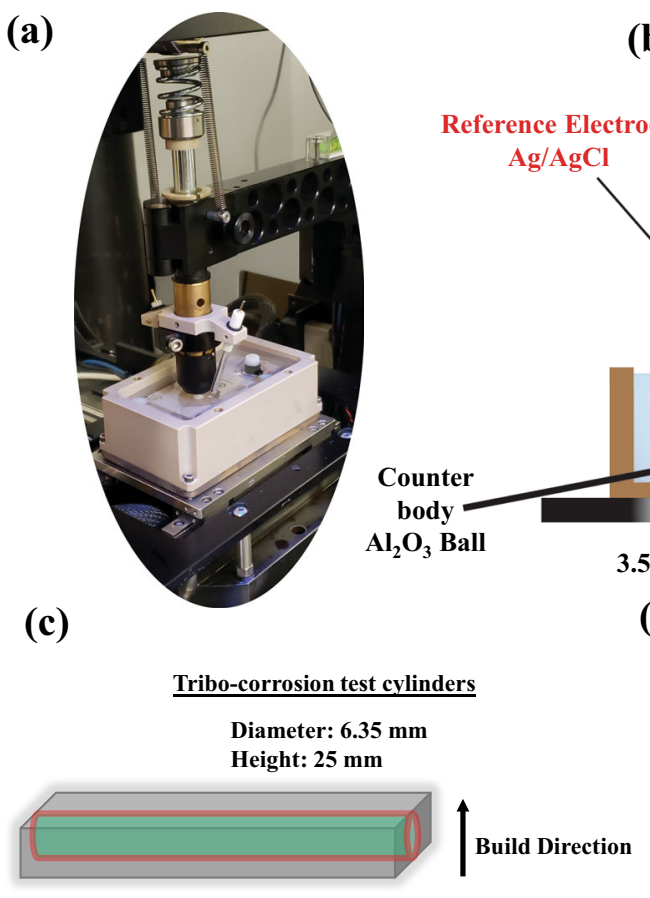

(b) Normal

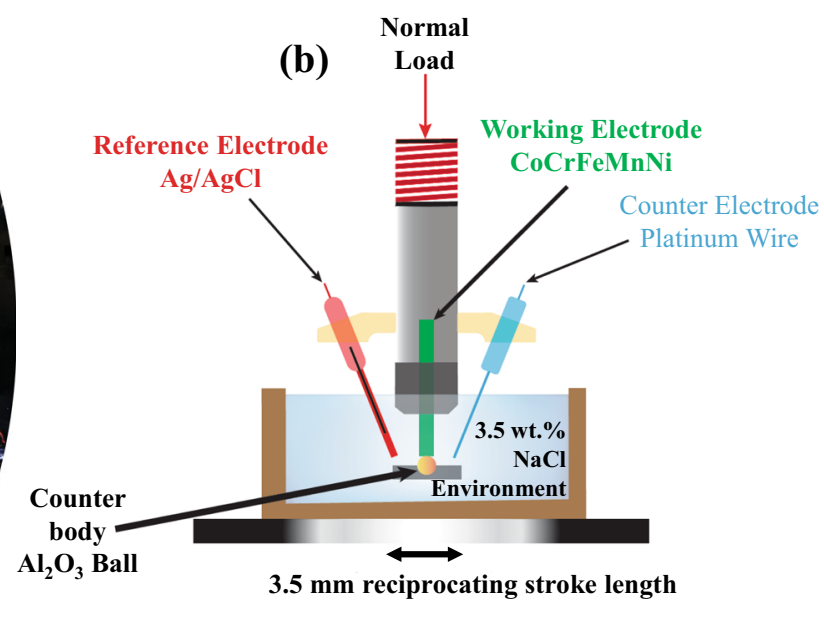

(d)

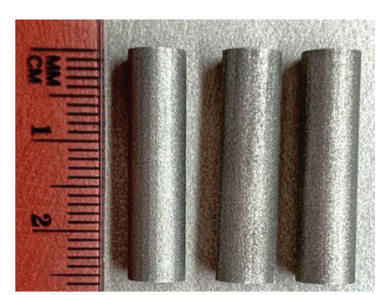

Fig. 5 Tribo-corrosion setup. a Tribo-corrosion module mounted on the tribometer. $\mathbf{b}$ Schematic representation of the tribo-corrosion test setup showing the three-electrode cell $(\mathrm{Ag} / \mathrm{AgCl}$ reference electrode, $\mathrm{CoCrFeMnNi}$ working electrode, and Platinum wire counter electrode) coupled with the flat-on-ball reciprocating contact $\left(\mathrm{Al}_{2} \mathrm{O}_{3}\right)$ in $3.5 \mathrm{wt} \% \mathrm{NaCl}$ environment. c Schematic of as-printed AM CoCrFeMnNi plates (build direction indicated by arrow) from which the tribo-corrosion cylindrical samples were cut out using electric discharge machining (EDM). d HEA working electrodes in the form of cylinders $6.35 \mathrm{~mm}$ in diameter and $25 \mathrm{~mm}$ in length.

The tribo-corrosion degradation mechanism for AM-ed CoCrFeMnNi HEA was distinctly different compared to its as-cast counterpart in $3.5 \mathrm{wt} \% \mathrm{NaCl}$ as discussed in the previous sections. The refined microstructure of the AM-ed CoCrFeMnNi HEA led to strengthening of the alloy and increased wear resistance compared to the as-cast CoCrFeMnNi. Furthermore, the AM-ed alloy had a more protective passive layer which may be attributed to the sub-grain cellular structure promoting better anchoring of the surface oxide ${ }^{47}$. In contrast, the as-cast CoCrFeMnNi HEA showed a less protective surface passivation layer resulting in extensive oxide pullout and severe abrasive wear.
In summary, the tribo-corrosion response and mechanism of AM-ed CoCrFeMnNi HEA was evaluated in $3.5 \mathrm{wt} \% \mathrm{NaCl}$ solution at room temperature and compared with the corresponding cast alloy. A significant anisotropy was seen in the tribo-corrosion response with $45^{\circ}$ to the $\mathrm{BD}$ showing the best performance. Both AM-ed and as-cast $\mathrm{CoCrFeMnNi}$ exhibited abrasive wear mechanism with the AM-ed alloy showing six times lower wear volume loss and five times lower wear rate compared to its as-cast counterpart. Superior tribo-corrosion resistance of $\mathrm{AM}$-ed $\mathrm{CoCrFeMnNi}$ was attributed to the refined microstructure and highly protective passivation layer promoted by the sub-grain cellular structure formed during AM. 


\section{METHODS}

\section{Laser-engineered net shaping}

CoCrFeMnNi plates with dimensions of $29 \mathrm{~mm} \times 10 \mathrm{~mm} \times 10 \mathrm{~mm}$ were additively manufactured using laser-engineered net shaping (LENS) on an OPTOMEC LENS 450 equipped with a $400 \mathrm{~W}$ Nd:YAG laser. Pre-alloyed CoCrFeMnNi powder with average particle size of $36.8 \mu \mathrm{m}$ was delivered from the powder feeder to the melt pool through four co-axial nozzles. A standard low-carbon steel plate with a thickness of $6.35 \mathrm{~mm}$ was used as the printing substrate. The standoff distance between the nozzles and workpiece was kept $\sim 9 \mathrm{~mm}$ to maintain deposition efficiency and stability. The processing chamber was filled with high-purity argon with the oxygen content maintained below $10 \mathrm{ppm}$ during printing. The processing parameters were optimized to obtain a near-fully dense printed plate as summarized in Table 2. Bi-directional scan strategy was used and the scan direction was rotated $90^{\circ}$ for obtaining consecutive layers. In parallel, equimolar CoCrFeMnNi alloy ingot was synthesized by vacuum/argon arc melting using high-purity elements (>99.9\%). The as-cast CoCrFeMnNi was flipped and re-melted five times for homogeneity.

\section{Surface analysis and microstructure characterization}

Surface morphology, microstructural characterization, and chemical composition of the AM-ed and as-cast CoCrFeMnNi HEAs were obtained using SEM (FEl Quanta-ESEM $200^{\mathrm{TM}}$ ) and EDS. X-ray diffraction analysis using Rigaku Ultima III with $1.54 \AA$ Cu- $\mathrm{K}_{a}$ radiation was performed to determine the crystal structure of the alloys. EBSD analysis was performed to determine the grain-size distribution and orientation. Surface topography and volume loss from tribo-corrosion was determined using noncontact white light interferometry (WLI, RTEC instruments, San Jose, CA, USA) and analyzed using Gwyddion software (version 2.55).

\section{Tribo-corrosion test}

Tribo-corrosion experiments were carried out on a reciprocating ball-on-flat tribometer (RTEC Instruments, San Jose, CA, USA) coupled with a potentiostat (Gamry Instruments, Ref-3000, Warminster, PA, USA) in accordance with ASTM G119. Figure 5a shows the tribo-corrosion module geometry. A schematic representation of the setup and test-configuration is shown in Fig. 5b. The electrochemical cell consisted of the HEA as working electrode (WE), platinum wire as counter electrode (CE), and $\mathrm{Ag} / \mathrm{AgCl}$ as reference electrode (RE). All three electrodes were placed within a proximity of $10 \mathrm{~mm}$ to increase sensitivity and reduce the ohmic drop. The working electrode with the dimensions of a cylinder with $6.35 \mathrm{~mm}$ diameter and $25 \mathrm{~mm}$ length (Fig. $5 \mathrm{c}, \mathrm{d}$ ) was cut from the AM-ed and as-cast plates of CoCrFeMnNi using electric discharge machining (EDM). $\mathrm{Al}_{2} \mathrm{O}_{3}$ balls of radius $6.35 \mathrm{~mm}$ were used as the counterbody at varying normal loads of $5 \mathrm{~N}, 10 \mathrm{~N}$, and $15 \mathrm{~N}$. The test parameters were selected based on the Hertzian contact pressure of the tribological contact. Tribo-corrosion tests were performed at room temperature systematically in the following steps:

- Open circuit potential (OCP) recorded for 3600 s (which was enough for OCP stabilization).

- Reciprocating sliding initiated under OCP conditions for $1800 \mathrm{~s}$ with changes in coefficient of friction (COF) and OCP monitored simultaneously.

- After reciprocating sliding for $1800 \mathrm{~s}$, OCP was stabilized for nearly $300 \mathrm{~s}$.

- All tests were repeated three times to determine reproducibility and obtain standard deviation for the measured data.

\section{DATA AVAILABILITY}

Majority of the data that support the findings of this study are included in this publication. Additional data are available upon reasonable request from the corresponding author.

Received: 1 March 2021; Accepted: 19 May 2021;

Published online: 11 June 2021

\section{REFERENCES}

1. Miracle, D. B. \& Senkov, O. N. A critical review of high entropy alloys and related concepts. Acta Mater. 122, 448-511 (2017).

2. Ayyagari, A. V., Gwalani, B., Muskeri, S., Mukherjee, S. \& Banerjee, R. Surface degradation mechanisms in precipitation-hardened high-entropy alloys. npj Mater. Degrad. 2, 33 (2018)
3. Pole, M., Sadeghilaridjani, M., Shittu, J., Ayyagari, A. \& Mukherjee, S. High temperature wear behavior of refractory high entropy alloys based on 4-5-6 elemental palette. J. Alloy. Compd. 843, 156004 (2020).

4. Nair, R. B. et al. Slurry erosion behavior of high entropy alloys. Wear 386-387, 230-238 (2017)

5. Ayyagari, A., Salloom, R., Muskeri, S. \& Mukherjee, S. Low activation high entropy alloys for next generation nuclear applications. Materialia 4, 99-103 (2018).

6. Mridha, S., Sadeghilaridjani, M. \& Mukherjee, S. Activation volume and energy for dislocation nucleation in multi-principal element alloys. Metals (Basel) 9, 263 (2019).

7. Ye, Y. F., Wang, Q., Lu, J., Liu, C. T. \& Yang, Y. High-entropy alloy: challenges and prospects. Mater. Today 19, 349-362 (2016).

8. Santos, E. C., Shiomi, M., Osakada, K. \& Laoui, T. Rapid manufacturing of metal components by laser forming. Int. J. Mach. Tools Manuf. 46, 1459-1468 (2006).

9. Thompson, S. M., Bian, L., Shamsaei, N. \& Yadollahi, A. An overview of direct laser deposition for additive manufacturing; part I: transport phenomena, modeling and diagnostics. Addit. Manuf. 8, 36-62 (2015).

10. Anderson, R., Terrell, J., Schneider, J., Thompson, S. \& Gradl, P. Characteristics of bi-metallic interfaces formed during direct energy deposition additive manufacturing processing. Metall. Mater. Trans. B 50, 1921-1930 (2019).

11. Luo, S., Su, Y. \& Wang, Z. Tailored microstructures and strengthening mechanisms in an additively manufactured dual-phase high-entropy alloy via selective laser melting. Sci. China Mater. 63, 1279-1290 (2020).

12. Schneider-Maunoury, C., Weiss, L., Acquier, P., Boisselier, D. \& Laheurte, P. Functionally graded Ti6Al4V-Mo alloy manufactured with DED-CLAD process. Addit. Manuf. 17, 55-66 (2017).

13. Uhlmann, E., Kersting, R., Klein, T. B., Cruz, M. F. \& Borille, A. V. Additive manufacturing of titanium alloy for aircraft components. Procedia CIRP 35, 55-60 (2015).

14. Basak, A. \& Das, S. Epitaxy and microstructure evolution in metal additive manufacturing. Annu. Rev. Mater. Res. 46, 125-149 (2016).

15. Carroll, B. E. et al. Functionally graded material of 304L stainless steel and inconel 625 fabricated by directed energy deposition: Characterization and thermodynamic modeling. Acta Mater. 108, 46-54 (2016).

16. Ren, J. et al. Corrosion behavior of selectively laser melted CoCrFeMnNi high entropy alloy. Metals (Basel) 9, 1029 (2019).

17. Pathak, S., Kumar, N., Mishra, R. S. \& De, P. S. Aqueous corrosion behavior of cast CoCrFeMnNi alloy. J. Mater. Eng. Perform. 28, 5970-5977 (2019).

18. Holcomb, G. R., Tylczak, J. \& Carney, C. Oxidation of CoCrFeMnNi high entropy alloys. JOM 67, 2326-2339 (2015).

19. Kim, Y.-K., Joo, Y.-A., Kim, H. S. \& Lee, K.-A. High temperature oxidation behavior of Cr-Mn-Fe-Co-Ni high entropy alloy. Intermetallics 98, 45-53 (2018).

20. Wang, P. et al. Additively manufactured CoCrFeNiMn high-entropy alloy via prealloyed powder. Mater. Des. 168, 107576 (2019).

21. Kim, Y. K., Choe, J. \& Lee, K. A. Selective laser melted equiatomic CoCrFeMnNi high-entropy alloy: microstructure, anisotropic mechanical response, and multiple strengthening mechanism. J. Alloy. Compd. 805, 680-691 (2019).

22. Li, R. et al. Selective laser melting of an equiatomic CoCrFeMnNi high-entropy alloy: processability, non-equilibrium microstructure and mechanical property. $J$. Alloy. Compd. 746, 125-134 (2018).

23. Melia, M. A. et al. Mechanical and corrosion properties of additively manufactured CoCrFeMnNi high entropy alloy. Addit. Manuf. 29, 100833 (2019).

24. Nartu, M. S. K. K. Y. et al. Enhanced tensile yield strength in laser additively manufactured Al0.3CoCrFeNi high entropy alloy. Materialia 9, 100522 (2020).

25. Stachowiak, A. \& Zwierzycki, W. Tribocorrosion modeling of stainless steel in a sliding pair of pin-on-plate type. Tribol. Int. 44, 1216-1224 (2011).

26. Adler, T. A. \& Walters, R. P. Corrosion and wear of 304 stainless steel using a scratch test. Corros. Sci. 33, 1855-1876 (1992).

27. Sun, Y. \& Rana, V. Tribocorrosion behaviour of AISI 304 stainless steel in $0.5 \mathrm{M} \mathrm{NaCl}$ solution. Mater. Chem. Phys. 129, 138-147 (2011).

28. Abd-El-Kader, H. \& El-Raghy, S. M. Wear-corrosion mechanism of stainless steel in chloride media. Corros. Sci. 26, 647-653 (1986).

29. Blau, P. J. et al. Future needs and challenges in tribo-corrosion research and testing. In Tribo-Corrosion: Research, Testing, and Applications (eds. Blau, P., Celis, J., Drees, D. \& Franek, F.) 214-226 (ASTM International, West Conshohocken, PA 2013). https://doi.org/10.1520/STP156320120051.

30. Shittu, J. et al. Biocompatible high entropy alloys with excellent degradation resistance in a simulated physiological environment. ACS Appl. Bio. Mater. 3, 8890-8900 (2020).

31. Brif, Y., Thomas, M. \& Todd, I. The use of high-entropy alloys in additive manufacturing. Scr. Mater. 99, 93-96 (2015).

32. Fujieda, T. et al. First demonstration of promising selective electron beam melting method for utilizing high-entropy alloys as engineering materials. Mater. Lett. 159, 12-15 (2015).

33. Xiang, S. et al. Microstructures and mechanical properties of $\mathrm{CrMnFeCoNi}$ high entropy alloys fabricated using laser metal deposition technique. J. Alloy. Compd. 773, 387-392 (2019). 
34. Chew, Y. et al. Microstructure and enhanced strength of laser aided additive manufactured CoCrFeNiMn high entropy alloy. Mater. Sci. Eng. A 744, 137-144 (2019).

35. Ayyagari, A. et al. Reciprocating sliding wear behavior of high entropy alloys in dry and marine environments. Mater. Chem. Phys. 210, 162-169 (2018).

36. Fujieda, T. et al. CoCrFeNiTi-based high-entropy alloy with superior tensile strength and corrosion resistance achieved by a combination of additive manufacturing using selective electron beam melting and solution treatment. Mater. Lett. 189, 148-151 (2017).

37. Chen, P., Li, S., Zhou, Y., Yan, M. \& Attallah, M. M. Fabricating CoCrFeMnNi high entropy alloy via selective laser melting in-situ alloying. J. Mater. Sci. Technol. 43, 40-43 (2020).

38. $\mathrm{Xu}, \mathrm{Z}$. et al. Microstructure and nanoindentation creep behavior of $\mathrm{CoCrFeMnNi}$ high-entropy alloy fabricated by selective laser melting. Addit. Manuf. 28, 766-771 (2019)

39. Li, S., Hassanin, H., Attallah, M. M., Adkins, N. J. E. \& Essa, K. The development of TiNi-based negative Poisson's ratio structure using selective laser melting. Acta Mater. 105, 75-83 (2016).

40. Gu, D., Shi, Q., Lin, K. \& Xi, L. Microstructure and performance evolution and underlying thermal mechanisms of $\mathrm{Ni}$-based parts fabricated by selective laser melting. Addit. Manuf. 22, 265-278 (2018).

41. Tong, Z. et al. Laser additive manufacturing of FeCrCoMnNi high-entropy alloy: effect of heat treatment on microstructure, residual stress and mechanical property. J. Alloy. Compd. 785, 1144-1159 (2019).

42. Zhang, B., Dembinski, L. \& Coddet, C. The study of the laser parameters and environment variables effect on mechanical properties of high compact parts elaborated by selective laser melting 316L powder. Mater. Sci. Eng. A 584, 21-31 (2013).

43. Pham, M.-S., Dovgyy, B., Hooper, P. A., Gourlay, C. M. \& Piglione, A. The role of side-branching in microstructure development in laser powder-bed fusion. Nat. Commun. 11, 749 (2020).

44. Calcagnotto, M., Ponge, D., Demir, E. \& Raabe, D. Orientation gradients and geometrically necessary dislocations in ultrafine grained dual-phase steels studied by 2D and 3D EBSD. Mater. Sci. Eng. A 527, 2738-2746 (2010).

45. Pejaković, V., Totolin, V. \& Rodríguez Ripoll, M. Tribocorrosion behaviour of Ti6Al4V in artificial seawater at low contact pressures. Tribol. Int. 119, 55-65 (2018).

46. Totolin, V. et al. Surface engineering of Ti6Al4V surfaces for enhanced tribocorrosion performance in artificial seawater. Mater. Des. 104, 10-18 (2016).

47. Kong, D. et al. The passivity of selective laser melted 316L stainless steel. Appl. Surf. Sci. 504, 144495 (2020)

\section{ACKNOWLEDGEMENTS}

Su.M. and H.A. acknowledge support from Partnership 2020: U.S.-India Higher Education Cooperation, a collaborative initiative between U.S. Department of State and University of Nebraska at Omaha. Su.M. and N.D. acknowledge support from Center for Agile \& Adaptive and Additive Manufacturing (CAAAM) funded through
State of Texas Appropriation \#190405-105-805008-220 and Materials Research Facility (MRF) at the University of North Texas. W.C. acknowledges support from the National Science Foundation (CMMI-1927621 and DMR-2004429) and UMass Faculty Startup.

\section{AUTHOR CONTRIBUTIONS}

J.S.: Conceptualization, additive manufacturing, methodology, investigation, formal analysis, writing. M.S.: Writing - review \& editing. M.P.: Formal analysis. Sa.M.: Investigation, methodology. J.R.: Additive manufacturing, writing - review \& editing. Y.L.: Additive manufacturing, formal analysis. I.T.: Additive manufacturing. H.A.: Validation, resources, writing - review \& editing. W.C.: Additive manufacturing, resources, supervision, writing - review \& editing. N.D.: Writing - review \& editing. Su.M.: Supervision, funding acquisition, resources, methodology, writing - review \& editing.

\section{COMPETING INTERESTS}

The authors declare no competing interests.

\section{ADDITIONAL INFORMATION}

Correspondence and requests for materials should be addressed to S.M.

Reprints and permission information is available at http://www.nature.com/ reprints

Publisher's note Springer Nature remains neutral with regard to jurisdictional claims in published maps and institutional affiliations.

cc) (i)

Open Access This article is licensed under a Creative Commons Attribution 4.0 International License, which permits use, sharing, adaptation, distribution and reproduction in any medium or format, as long as you give appropriate credit to the original author(s) and the source, provide a link to the Creative Commons license, and indicate if changes were made. The images or other third party material in this article are included in the article's Creative Commons license, unless indicated otherwise in a credit line to the material. If material is not included in the article's Creative Commons license and your intended use is not permitted by statutory regulation or exceeds the permitted use, you will need to obtain permission directly from the copyright holder. To view a copy of this license, visit http://creativecommons. org/licenses/by/4.0/.

(c) The Author(s) 2021 